\title{
Potential and Barriers to Adoption of в 2 в E-Commerce in SMES in Transition Economies: Case of Albania
}

\author{
NARASIMHA RAO VAJJHALA \\ American University of Nigeria, Nigeria \\ Narasimha.vajjhala@aun.edu.ng \\ SALU GEORGE THANDEKKATTU \\ American University of Nigeria, Nigeria \\ george.thandekkattu@aun.edu.ng
}

Small- and Medium-sized Enterprises (SMEs) can benefit significantly from investments in e-commerce and e-business. However, the adoption of e-commerce has been quite slow and limited among SMES, especially in transition economies. Interviews were conducted with senior managers from 30 medium-sized enterprises in a transition economy - Albania, three from each of the ten key sectors, namely, information and communication technology (Іст), tourism, banking, financial services, agriculture, healthcare, logistics, manufacturing, construction, and retailing. The qualitative data coded from the in-depth interviews was analysed using Nvivo ${ }^{\circledR}$ for identifying key themes. Four key themes were identified along with ten subthemes. This study identified the four key themes that can guide the organizational leadership of medium-sized enterprises in transition economies in strategically leveraging e-commerce technology. The four key themes identified in this study include resource constraints, external environmental factors, organizational issues, and resistance to acceptance of new technology. The identification of the key barrier factors will help the organizational leadership in transition economies, such as Albania devise strategies to promote adoption of e-commerce in the smes. The findings of this study will help the organizational leadership of SMES in transition economies identify measures to address and resolve the barriers to adoption of e-commerce. This study also adds value to the limited literature on barriers to e-commerce adoption in the context of SMES in transition economies. The study offers insights on e-commerce adoption by smes, which can be applied to other transition and emerging economies attempting to understand the barriers that might hinder the adoption of e-commerce by the smes.

Key words: barriers, e-commerce, e-business, challenges, transition, Albania https://doi.org/10.26493/1854-4231.12.155-169 


\section{Introduction}

The category of micro, small and medium-sized enterprises (smes) is made up of enterprises which employ fewer than 250 persons and which have an annual turnover not exceeding 50 million euro, and/or an annual balance sheet total not exceeding 43 million euro (European Commission 2016b). E-Commerce is defined as the process of selling, buying, and exchanging products and services over the Internet (Turban, McLean, and Weatherbe 2004). E-Commerce can be a key source of competitive advantage to SMES by reducing the cost of doing business, improving the quality of products, and creating new avenues for selling existing products (Sutanonpaiboon and Pearson 2006). Solaymani, Sohaili and Yazdinejad (2012) stated that adoption of e-commerce by SMES in developing countries is one of the key indicators of economic growth. Some of the benefits of e-commerce for SMEs include reduced cycle time, increased market reach, reduced operational costs, reduced operational and marketing costs as well as improved customer service (Jahanshahi, Zhang, and Brem 2013).

However, to leverage these benefits, smes need to overcome and resolve the barriers to e-commerce adoption. Most of the earlier studies have explored either how e-commerce businesses have evolved over the last couple of decades or have explored how ecommerce adoption has benefitted firms in developed countries. There is limited literature exploring how SMES, especially in transition economies, have adopted e-commerce. Although SMes are increasingly adopting e-commerce, their use and exploitation is limited in scope and not up to the potential (Scupola 2009). There is also limited literature on the barriers to adoption of e-commerce in SMES in transition economies, such as Albania.

Although the terms e-commerce and e-business are often used interchangeably, some of the researchers have differentiated between these two terms. According to Laudon and Traver (2016), e-business refers to the digital enabling of transactions and processes within a firm's organizational boundaries whereas e-commerce includes transactions involving the change of value transcending organizational boundaries (Laudon and Traver 2016). Several e-commerce business models have come up over the last few decades, often hybrids of the existing major models. The three major models of e-commerce, include в 2в model (Business-to-Business), в2 с model (Business-to-Consumer), and the $\mathrm{c} 2 \mathrm{C}$ model (Consumer-to-Consumer). The вгв model is the largest model in the context of the mon- 
etary value of exchanges with the total value of the exchanges exceeding $\$ 14$ trillion in 2015 globally and around $\$ 6.3$ trillion in the us (Laudon and Traver 2016). B2C is the next key model in the context of the monetary value of exchanges totalling around $\$ 530$ billion in the us in 2015 .

Laudon and Traver (2016) also state that only $10 \%$ of the dot-coms formed since 1995 have survived as of 2015 with a tiny percentage of them still serving as profitable ventures. Hence, understanding the factors that might be barriers to SMEs adopting e-commerce and e-business models is quite relevant as a failure in implementation might have catastrophic effects on the survival of these smes. Most of the SMES, in particular, in developing and transition economies are often limited by financial and human resources. Any investment that these SMEs make in e-commerce and e-business adoption takes a significant chunk of their meagre resources; hence, any failure in implementation will have a significant negative effect on the survival of these firms. Understanding the factors that might inhibit the successful implementation of e-commerce and e-business operations will help the organizational leaders in planning and taking remedial measures before investing significant resources in the adoption of e-commerce.

Each of the three most important categories of e-commerce business models can be categorized into several other business models each of which may have one of more revenue models. The various categories of в 2 c business models include e-tailer, community provider, content provider, portal, transaction broker, and market creator, the service provider (Laudon and Traver 2016). The various categories of в 2 в business models include private industrial networks and net marketplaces, which can be further categorized as e-distributor, e-procurement, exchanges, and industry consortiums (Laudon and Traver 2016).

The two major models, namely в 2в and в2с offer additional avenues to SMES to streamline their existing business operations as well as processes and also explore new opportunities to reach global markets. In this study, the focus was on the вгв business model because в2 model is not suitable for all SmEs while в2в business model could be helpful for SMEs. The central research question driving this study is 'What are the key inhibitors of business-to-business e-commerce adoption and implementation in Albanian smes?' To answer this research question, empirical data was collection from SMES in the capital city of Tirana where more than $70 \%$ of the smes are located (European Commission 2016c). 


\section{Literature Review}

SMALL- AND MEDIUM-SIZED ENTERPRISES (SMES)

IN TRANSITION ECONOMIES

Several benchmarks are used by international organizations and governments to define the categorized of firms as micro, small, medium, and large enterprises. In this article, the definition provided by European Commission (2016a) is used for categorizing a firm as an SME because the transition economy referred to in this country - Albania is a European Union candidate country aspiring for a full member status. As per the Eu recommendation 2003/361, the two key factors based on which a firm is categorized as an SME are the staff headcount and either the turnover or the balance sheet total of the enterprise. A business is categorized as a micro-sized firm if the staff headcount of the company is less than ten members and if either the turnover or balance sheet total is less than 2 million Euros (European Commission 2016a). In this study, micro-sized firms are not included because of their relatively small size because of which they may not have adequate resources to benefit from investments in electronic commerce completely. A business can be categorized as a small-sized firm if the staff headcount is less than 50 members and if the turnover or the balance sheet total is less than 10 million Euros (European Commission 2016a). A firm can be categorized as a medium-sized firm if the staff headcount is less than 250 members and if the turnover is either less than 50 million Euros or the balance sheet total is less than 43 million Euros (European Commission 2016a). In this study, we have included both small- and medium-sized firms.

SMES contribute significantly to the economic growth and employment generation in emerging economies (Subrahmanya 2015; Wonglimpiyarat 2015). SMEs accounted for $99.8 \%$ of all enterprises in the non-financial business sector in the European Union employing over 90 million people contributing to over $67 \%$ of total employment (European Commission 2016b). According to European Commission SBA report (2016c), SMES constitute $99.8 \%$ of total businesses in Albania contributing to $79.9 \%$ of the total employment and $67.8 \%$ of total value added in the non-financial economy.

Researchers have used different criteria to categorize countries as transition economies. The categorization criteria used by Vasyechko (2012) is used in this study to categorize the transition economy into three categories, namely, Central and East European economies, emerging economies, and rent-seeking economies of Africa and the 
Middle East. Albania is part of the first category of the transition economies that are gradually moving from a central planning system to a free market economy (Šliburytè and Masteikienè 2011; McKenzie and Merrilees 2008). International Monetary Fund (IMF) has listed out some of the key criteria for the process of transition, including liberalization, restructuring, privatization, and institutional reforms (Šliburytė and Masteikienè 2011). While some of the other Central and East European countries had a smooth transition process, Albania had a different experience as the communist regime in Albania, as in several other countries taken over by the communist revolution, suppressed individualism, personal freedom, and freedom of expression (Prasnikar, Pahor, and Svetlik 2008). The transition process in Albania was marred by brief episodes of social, political, and economic strife. As of the time of this study, Albania had achieved the candidate country status and is in the process of undertaking reforms needed for Albania to obtain full member status with the European Union.

\section{BARRIERS TO E-COMMERCE ADOPTION FOR SMES}

SMES can benefit significantly from the adoption and use of ecommerce (Scupola 2009). Most of the smes only have a presence over the World Wide Web through their websites that are used for advertising their products and services, but a significant of these firms still do not conduct e-commerce (Sutanonpaiboon and Pearson 2006). SMES can benefit from productivity gains at a firm level with e-commerce technologies as they can gain access to supply and distribution chains that were previously not connected (Jahanshahi, Zhang, and Brem 2013). E-Commerce also has the potential of improving the information flow and decreasing the inefficiency and transaction costs for SMES (Jahanshahi, Zhang, and Brem 2013). Technological innovation is quite essential for SMEs to promote firm performance and growth. According to Subrahmanya (2015), successful innovation activity will help establish a positive competitive position leading to a sustainable competitive advantage and improved firm performance. smes that have not yet implemented e-commerce can demonstrate technological innovation through the adoption of electronic commerce technologies.

Several barriers influence the adoption of e-commerce by SMEs, including a slower technology adoption rate because of lack of staff in key areas, including information technology and small management teams (Sutanonpaiboon and Pearson 2006). Some of the key barriers to adoption of e-commerce by SMEs identified by re-

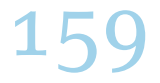


searchers include e-commerce infrastructure, market size, awareness, telecommunications infrastructure, legal systems, government regulations, limited knowledge of models, etc. (Zaied 2012). The most significant factors that influence the adoption of e-commerce in SMES include top management support, employees' knowledge and attitude towards the use of information systems, and resource constraints in the firms (Mirchandani and Motwani 2001; Dholakia and Kshetri 2004; Scupola 2009).

Kaynak, Tatoglu, and Kula (2012) categorized the barriers into three categories, namely, economic barriers, cognitive barriers, and socio-political barriers. This categorization of the barrier factors allows for grouping of the various inhibiting factors acting as barriers to e-commerce adoption. The economic factors include the limited financial resources of most of the SMES, especially in transition economies like Albania. Jahanshahi, Zhang, and Brem (2013) list out factors such as the high cost of user support as well as running and maintenance costs as some of the reasons why smes do not consider e-commerce as a viable financial investment. The lack of adequate funds impedes the ability of SMEs to invest in the infrastructure and technology required to establish в 2в platforms and services. The cognitive barriers include the acceptance of new technology by the staff of these firms.

Several studies focused on the technology acceptance behaviour, especially in the context of SMES. Zaied (2012) provided a comprehensive categorization of various barriers to adoption of e-commerce by SMES in Egypt. These categories include social and cultural barriers, technical barriers, economic barriers, political barriers, organizational barriers, and legal as well as regulatory barriers (Zaied 2012). Some of the key barriers from each of these categories include lack of e-commerce infrastructure, competitive pressures, lack of management support, and lack of regulatory systems (Zaied 2012).

\section{Methodology}

In this qualitative study, data was gathered using interviews and observations. Interviews were conducted with senior managers from 30 medium-sized enterprises, three from each of the ten key sectors, namely, Information and Communication Technology (Іст), Tourism, Banking, Financial Services, Agriculture, Healthcare, Logistics, Manufacturing, Construction, and Retailing. The selection of the sectors of the SMES was based on the SME performance review released by the European Commission in its annual report for 2015-6. Participants were on average $35(\mathrm{SD}=8.42)$ years of age almost evenly 
split between male (52\%) and female (48\%). More than half (56\%) had completed an undergraduate degree, and $44 \%$ had completed a graduate degree. Participants had $10.5(\mathrm{SD}=5.86)$ years of work experience.

The 30 small- and medium-sized firms chosen for the sample were from ten key economic sectors. These ten economic sectors represent more than $75 \%$ of the total number of SMEs in Albania. Yin (2009) recommended replication rather than sampling logic for multisite case studies. According to Eisenhardt (1989), using multiple cases within each category allows findings to be replicated within categories. As the study involved in-depth interviews, the data generated from the interviews with the 30 participants' generated significant data required for generating themes. The human resource managers from these 30 medium-sized companies were approached and based on their recommendations; three employees at medium and senior management levels were selected. The criteria for selection of the employees were fluency in English and, at least, three years of work experience. The level of experience was an essential criterion, as the employees need to have an understanding of strategic objectives of the firm. Informed consent was obtained from the employees before data collection. The participants were also provided with the key terms to be used in the interviews. The interviews were conducted over a one-year period. All interviews were audiorecorded, and the interviews were transcribed. Publically accessible documents, as well as field notes, were also included as data sources.

Quantitative methods were considered but were not chosen for this study because barrier factors cannot be examined through quantitative methods. This is because most of these factors were identified from the intrinsic knowledge available from prior experience of the managers. According to Gelo, Braakmann, and Benetka (2008), quantitative studies require the reduction of phenomena to numerical values to undertake statistical analysis. However, according to McDaniel and Gates (2007), Qualitative research is useful when findings are not subject to quantification or quantitative analysis. The central research purpose driving this study was to identify the key inhibitors of business-to-business e-commerce adoption and implementation in Albanian smes. As such, understanding, the experience and perspective of senior management were quite critical. Hence, the qualitative research methodology was used in this study.

Table 1 shows the demographic information of the respondents. Respondents with varied experience, age, and gender were chosen to alleviate any bias because of these demographic factors. 
TABLE 1 Demographic Statistics

\begin{tabular}{llr}
\hline Category & Criteria & Percentage \\
\hline Gender & Male & 53 \\
& Female & 47 \\
\hline Age & $20-30$ years & 26 \\
& 30-40 years & 37 \\
& $40-50$ years & 23 \\
& $>50$ years & 14 \\
\hline Experience & $1-5$ years & 25 \\
& 5-10 years & 52 \\
& $>10$ years & 23 \\
\hline
\end{tabular}

Nvivo $^{\circledast} 11$ which is Computer-Assisted Qualitative Data Analysis Software (CAQDAS) software was used for this study. Nvivo ${ }^{\circledR}$ software has several advanced features for analysing qualitative data, including in-vivo coding, case and theme coding, comparison diagrams, relationship coding, and matrix coding. An Nvivo ${ }^{\circledR}$ project was created, and the interview data previously transcribed into word document was uploaded into the source section of the software. The first set of data analysis resulted in the creation of nine themes. Additional reading and thorough analysis of the data and using axial coding resulted in the nine themes further reduced into four themes with ten subthemes. The four key themes are resource constraints, external environmental factors, organizational issues, and resistance to acceptance of new technology. Using $\mathrm{Nvivo}^{\circledast}$, queries were run to discover patterns, relationships and different phenomena in the primary transcribed interviews from the respondents. Using the text search-analytical tool in $\mathrm{Nvivo}^{\oplus}$ the repeated occurrence of words within the interviews was identified. This helped to identify the number of times certain words were used by subjects throughout the length of the interview.

\section{Discussion}

The four key themes are resource constraints, external environmental factors, lack of top management support, and resistance to acceptance of new technology. The themes and subthemes identified in this study are listed out in table 2. A total of 10 subthemes were identified in the study.

THEME 1: RESOURCE CONSTRAINTS

Nineteen out of 30 respondents (63\%) agreed that SMEs face resource constraints considering their small size, especially in the 
TABLE 2 Themes and Subthemes Identified in the Study

\begin{tabular}{|c|c|}
\hline 1. Resource constraints & $\begin{array}{l}\text { - Lack of human resources } \\
\text { - Lack of financial resources } \\
\text { - Lack of technological resources }\end{array}$ \\
\hline 2. External environmental factors & $\begin{array}{l}\text { - Government policies and initiatives } \\
\text { - Security and privacy } \\
\text { - Infrastructural issues }\end{array}$ \\
\hline 3. Organisational issues & $\begin{array}{l}\text { - Support from top management } \\
\text { - Organisational culture }\end{array}$ \\
\hline $\begin{array}{l}\text { 4. Resistance to acceptance of new } \\
\text { technology }\end{array}$ & $\begin{array}{l}\text { - Perceived usefulness of new technology } \\
\text { - Training workforce }\end{array}$ \\
\hline
\end{tabular}

context of transition economies like Albania. This theme was further divided into three subthemes, namely, lack of human resources, lack of financial resources, and lack of technological resources. As compared to other developed economies, the SMES in transition economies as well as developing economies do not have to the similar level of resources.

Twenty-three of the 30 respondents $(77 \%)$ indicated that will have major problems in allocating the already exhausted and strained resources for e-commerce adoption. Respondent R13 stated that 'My firm has limited financial and human resources to meet our operational requirements; we will struggle to find resources to allocate them for investing in e-commerce technologies.' Respondent R1 also expressed similar views by stating, 'My firm already has experienced tough times over the last few years with limited financial resources, we want to invest in e-commerce, but under the current circumstances I am not quite optimistic about investment in e-commerce.' Wonglimpiyarat (2015) stated that SMEs often face barriers in the context of low capitalization and insufficient assets. SMEs often face difficulties in accessing new capital required to implement technological investments.

Twenty-six out of $30(87 \%)$ of the respondents agreed that finding appropriate human resources to manage the e-commerce operations was a major barrier to the adoption of e-commerce. Respondent R22 stated that 'We do not have adequate human resources i.e. employees with knowledge and experience in using e-commerce operations. We cannot invest in hiring such employees as this is not in our short-term plan.' Twenty-eight out of 30 respondents (93\%) agreed that investment in human resources is essential for the successful adoption of e-commerce technologies but also emphasized on the problems their firms are facing with hiring an additional workforce. 
Respondent R5 stated, 'We want to invest in hiring new staff members to handle the technological requirements of e-commerce, but the costs involved are quite high as we need qualified and highly skilled employees.' Esmaeilpour, Hoseini, and Jafarpour (2016) list lack of qualified and trained personnel as one of the key barriers to entrepreneurship in the field of e-commerce.

THEME 2: EXTERNAL ENVIRONMENTAL FACTORS

Eighteen out of the 30 respondents $(60 \%)$ identified external environmental factors, which are out of the control of the firms as a key barrier to adoption of e-commerce by their firms. This theme also includes three subthemes, namely, government policies and initiatives, security and privacy, and infrastructural issues. Respondent R17 stated that 'Some of the problems that we have with the adoption of e-commerce are out of our control, we have problems with lack of clarity in regulations as there is no clear policy.' Respondent R11 also expressed similar view stating 'the government should help us understand the policies and also establish a government regulation in alignment with the European standards.'

Twenty-one out of the 30 respondents (70\%) accepted that they were not aware of any precise governmental strategy or policy encouraging e-commerce for SMEs. Twenty-four out of the 30 respondents $(80 \%)$ emphasized on the setting up of a clear policy outlining the legal guidelines and government assistance to encourage adoption of e-commerce by SMEs. According to Respondent R29, 'SMES employ most of the people in the country, so there is a need for a dedicated governmental policy and assistance for smes to adopt ecommerce.' Respondent R14 also stated similar view by stating 'the European Union should include some assistance so that Albanian SMES are encouraged to adopt e-commerce.' According to Ahmad (2012), some of the challenges that Smes often face include bureaucratic procedures, complex taxation and registration system, poorly designed intellectual property rights, and the unfavourable business regulatory environment. The Albanian government has been taking several administrative and legal reforms as part of the process of joining the European Union. Hence, these potential barriers could be resolved over the next few years as Albanian government tries to synchronize its policies and regulations to meet European standards. These findings are consistent with those of Esmaeilpour, Hoseini, and Jafarpour (2016) who list out government support and presence of legal framework as key enablers for adoption of e-commerce by SMES. 
Nineteen out of 30 respondents $(63 \%)$ were concerned about the security and privacy issues and indicated these issues as key barriers to adoption of e-commerce. Eighteen out of 30 respondents (60\%) cited lack of proper infrastructure as a key barrier to adoption of ecommerce. Some of the small- and medium-sized firms were located at distant rural locations and did not have the same level of internet penetration as those in the urban areas. In addition, some of the operations of these firms were in locations where proper infrastructure required for e-commerce operations was not available.

\section{THEME 3: ORGANIZATIONAL ISSUES}

Twenty-four out of 30 respondents (80\%) indicated that organizational issues were a key barrier to the adoption of e-commerce. This theme was further divided into two subthemes, namely, support from top management and organizational culture. Twenty-five of the 30 respondents $(83 \%)$ emphasized the importance of top management support. According to Respondent R23 'Support from top management is crucial for success of any major initiative in SMES and ecommerce adoption is not an exception' Respondent R15 also advocated the support from top management by stating 'Albanian culture is high on power distance and employees tend to accept new initiatives that are supported by top management.' Nineteen of the 30 respondents (63\%) indicated that organizational culture of a firm has a bearing on the adoption of e-commerce. Respondent R1 stated that 'in some organizations the culture is to promote new ideas and innovation, in such organizations the chances of adoption of e-commerce are higher' Respondent R19 also expressed similar concerns stating 'top management should promote the establishment of organizational culture where new technological initiatives are promoted.'

\section{THEME 4: RESISTANCE TO ACCEPTANCE OF NEW TECHNOLOGY}

Twenty-three out of the $30(77 \%)$ respondents expressed the view that a key barrier to adoption of e-commerce is likely to be the resistance to acceptance of new technologies in the firm. This theme is further subdivided into two subthemes namely, perceived usefulness of new technology and training workforce. Twenty out of the 30 respondents $(67 \%)$ expressed the view that the perceived usefulness of new technology is likely to have an influence on the way the employees react to the changes in their work. Respondent $\mathrm{R} 22$ stated 'Management need to ensure that there is awareness and understanding among employees about e-commerce so that employees understand the need for the new changes.' Respondent R29 stated 
that 'Resistance to new technology will be limited if employees are integrated into the change from the beginning and are considered as key stakeholders in the adoption process.' According to Rizzuto, Schwarz, and Schwarz (2014), psychological issues related to employee resistance to adoption of new technologies is a key barrier to the successful adoption of new technology in a firm. Hence, the organizational leadership of SMEs needs to take into consideration the influence of these factors and take measures to address this issue.

Twenty-seven out of the 30 respondents (90\%) emphasized the importance of training employees about the new technology. Respondent R25 stated 'Training needs to start early and incentives should be provided to those employees who embrace the new technology' Respondent R28 stated that 'Staff training is a critical component for the introduction of new technology or processes otherwise employee resistance is likely to be higher.'

\section{Limitations}

This study has some limitations, primarily about generalizing the findings to all the Albanian smes as the data was collected from key sectors in the SMES from the capital city. However, some of these might not apply to certain categories of SMES where e-commerce might not yield the similar level of benefits as in other sectors. Similarly, the study is limited to just one transition economy - Albania - and might not necessarily be true for other transition economies, which might not share similar socio-political and economic conditions. The study is limited by the honesty of the participants' responses during interviews and the amount of time available to conduct the study. Validity of the study is limited to the reliability of the instruments used. The study is limited also by the lack of literature on e-commerce in Albania.

\section{Conclusions, Limitations and Directions for Future Research}

This study identified the four key themes that can guide the organizational leadership of medium-sized enterprises in transition economies in strategically leveraging e-commerce technology. The four key themes identified in this study include resource constraints, external environmental factors, organizational issues, and resistance to acceptance of new technology. The ten subthemes identified in this study include lack of human resources, lack of financial resources, lack of technological resources, government policies and initiatives, security and privacy, infrastructural issues, support from 
top management, organizational culture, perceived usefulness of new technology, and training workforce. However, this study could provide the basis for further studies and provide a framework for researchers seeking to investigate potential barriers to adoption of e-commerce by SMEs in other transition economies. Future studies could explore other transition economies. Future research could include further investigation into factors, such as the influence of age and gender on adoption of e-commerce. Researchers could also investigate the extent of e-commerce adoption on a sector-wise basis as well as a location-wise basis.

\section{References}

Ahmad, S. Z. 2012. 'Micro, Small and Medium-Sized Enterprises Development in the Kingdom of Saudi Arabia: Problems and Constraints.' World Journal of Entrepreneurship, Management, and Sustainable Development 8 (4): 217-32.

Dholakia, R. R., and N. Kshetri. 2004. 'Factors Impacting the Adoption of the Internet among smes.' Small Business Economics 23 (4): 311-22.

Eisenhardt, K. M. 1989. 'Building Theories from Case Study Research.' Academy of Management Review 14(4): 532-50.

European Commission. 2016a. 'Commission Recommendation of 6 May 2003 Concerning the Definition of Micro, Small and Medium-Sized Enterprises (2003/361/Ec).' Official Journal of the European Union, L 124, 36-41.

- 2016b. Annual Report on European Smes 2014/2015: SMes Start Hiring Again. Brussels: European Commission.

- 2016c. '2016 SBA Fact Sheet: Albania.' European Commission, Brussels.

Gelo, O., D. Braakmann, and G. Benetka, G. 2008. 'Quantitative and Qualitative Research: Beyond the Debate.' Integrative Psychological and Behavioral Science 42 (3): 266-90.

Jahanshahi, A. A., S. Zhang, and A. Brem. 2013. 'E-Commerce for SMES: Empirical Insights from Three Countries.' Journal of Small Business and Enterprise Development 20 (4): 849-65.

Esmaeilpour, M., S. Y. Hoseini, and Y. Jafarpour. 2016. 'An Empirical Analysis of the Adoption Barriers of E-commerce in Small and Medium sized Enterprises (smes) with implementation of Technology Acceptance Model.' Journal of Internet Banking and Commerce 21 (2): 1-23.

Kaynak, E., E. Tatoglu, and V. Kula. 2005. 'An Analysis of the Factors Affecting the Adoption of Electronic Commerce by smes: Evidence from an Emerging Market.' International Marketing Review 22 (6): $632-40$. 
Laudon, K. C., and C. G. Traver. 2016. E-Commerce 2016: Business, Technology, \& Society. New York: Pearson.

McDaniel, C., and R. Gates. 2007. Marketing Research Essentials. New York: Wiley.

McKenzie, B., and B. Merrilees. 2008. 'Cross-Cultural Research in Transition Economies: A Marketing Perspective: From Theory to Practice.' Journal of East-West Business 14:119-46.

Mirchandani, A. A., and J. Motwani. 2001. 'Understanding Small Business Electronic Commerce Adoption: An Empirical Analysis.' Journal of Computer Information Systems 41 (3): 70-3.

Prasnikar, J., M. Pahor, and J. Svetlik. 2008. 'Are National Cultures Still Important in International Business? Russia, Serbia and Slovenia in Comparison.' Management 13:1-26.

Rizzuto, T. E., A. Schwarz, and C. Schwarz. 2014. 'Toward a Deeper Understanding of Iт Adoption: A Multilevel Analysis.' Information and Management 51 (1): 479-87.

Scupola, A. 2009. 'smes' E-Commerce Adoption: Perspectives from Denmark and Australia.' Journal of Enterprise Information Management 22 (1-2): 152-66.

Sliburytè, L., and R. Masteikienè. 2011. 'Adaption to Globalization Process in European Transition Economies.' Economics \& Management 16:404-10.

Solaymani, S., K. Sohaili, and E. A. Yazdinejad. 2012. 'Adoption and Use of E-Commerce in SMEs.' Electronic Commerce Research 12 (3): 24963.

Subrahmanya, M. H. B. 2015. 'Innovation and Growth of Engineering SMES in Bangalore: Why do Only Some Innovate and Only Some Grow Faster?' Journal of Engineering and Technology Management 36 (1): $24-40$.

Sutanonpaiboon, J., and A. M. Pearson. 2006. 'E-Commerce Adoption: Perceptions of Managers/Owners of Small- and Medium-Sized Enterprises (smes) in Thailand.' Journal of Internet Commerce 5 (3): 53-82.

Turban, E., E. McLean, and J. Wetherbe. 2004. Information Technology for Management: Transforming Organizations in the Digital Economy. New York: Wiley.

Vasyechko, O. 2012. 'A Review of FDI Theories: An Application for Transition Economies.' International Research Journal of Finance \& Economics 2 (89): 118-37.

Wonglimpiyarat, J. 2015. 'Challenges of SMEs Innovation and Entrepreneurial Financing.' World Journal of Entrepreneurship, Management, and Sustainable Development 11 (4): 295-311.

Yin, R. K. 2009. Case Study Research Designs and Methods. 4th ed. Thousand Oaks, cA: Sage.

Zaied, A. N. H. 2012. 'Barriers to E-Commerce Adoption in Egyptian 
Potential and Barriers to Adoption of в2в E-Commerce

smes.' International Journal of Information Engineering and Electronic Business 3 (1): 9-18.

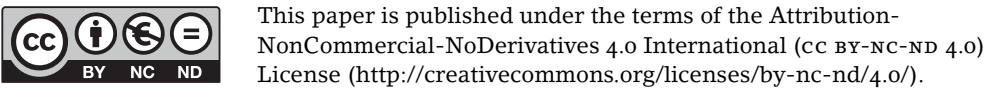

